\section{Commentary: The confirmation}

\author{
Antonio Miceli, $\mathrm{MD}, \mathrm{PhD}$
}

In the last years, the concept of aortic valve replacement (AVR) has been thoroughly revolutionized. Randomized controlled trials have shown noninferiority of transcatheter AVR over surgical AVR in medium- and low-risk patients with severe aortic stenosis. ${ }^{1}$ Thus, a number of patients with severe aortic stenosis will undergo transcatheter AVR. Nevertheless, surgical AVR still remains the gold standard treatment for aortic valve disease, as surgical bioprostheses have shown excellent hemodynamic performance with high freedom from structural valve degeneration and reoperation at very long-term follow-up. ${ }^{2}$ According to the German Aortic Valve Registry (GARY), the use of transcatheter AVRs has dramatically increased by $160 \%$ from 2013 to 2017; however, the amount of surgical procedures have also increased by $120 \%{ }^{3}$ These sustained numbers are possible thanks to new valve technologies. Among these, sutureless valves represent a hybrid solution between the percutaneous and surgical treatment. Perceval (LivaNova, plc, London, United Kingdom) is a self-expanding prosthesis designed as an alternative to traditional prosthesis to simplify surgical implantation. Specifically, it gives the advantage of removing the diseased valve and avoids the need for sutures after annular decalcification, reducing aortic crossclamp and cardiopulmonary bypass. Available evidence suggests that the use of Perceval is associated with excellent postoperative outcomes and facilitates the minimally invasive approach. ${ }^{4,5}$ Long-term results are promising. ${ }^{6}$ Compared with standard prosthesis, a meta-analysis has shown sutureless valves are associated with shorter operative times, lower incidence of postoperative renal failure, fewer blood transfusions, better hemodynamic performances, and

\footnotetext{
From the Minimally Invasive Cardiac Department, Istituto Clinico Sant'Ambrogio, Milano, Italy

Disclosures: Antonio Miceli is a consultant for LivaNova.

The Journal policy requires editors and reviewers to disclose conflicts of interest and to decline handling or reviewing manuscripts for which they may have a conflict of interest. The editors and reviewers of this article have no conflicts of interest.

Received for publication Dec 7, 2020; revisions received Dec 7, 2020; accepted for publication Dec 7, 2020; available ahead of print Dec 13, 2020.

Address for reprints: Antonio Miceli, MD, PhD, Minimally Invasive Cardiac Department, Istituto Clinico Sant'Ambrogio, Via LG Faravelli 16, Milano, Italy (E-mail: Antoniomiceli79@alice.it).

J Thorac Cardiovasc Surg 2021;161:935-6

$0022-5223 / \$ 36.00$

Copyright (C) 2020 by The American Association for Thoracic Surgery

https://doi.org/10.1016/j.jtcvs.2020.12.018
}

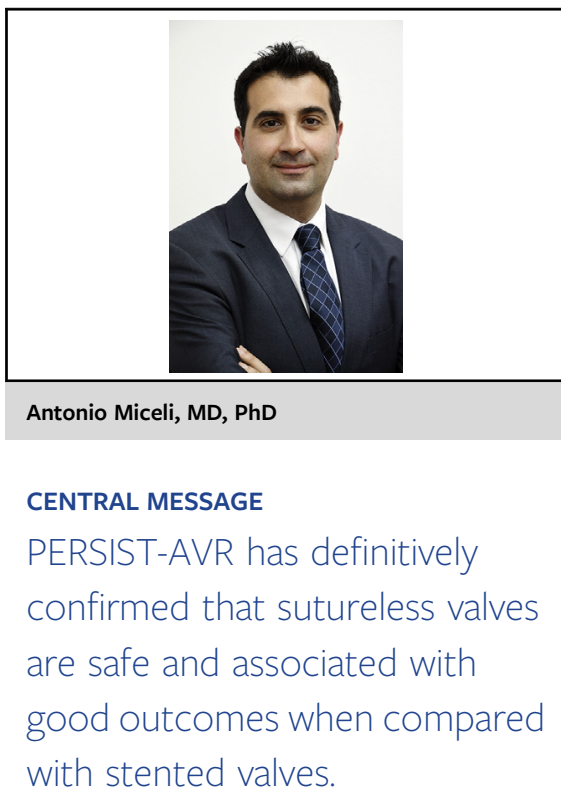

a greater incidence of pacemaker implantation. Mortality, stroke, and paravalvular leakage rate were similar. ${ }^{7}$ However, the retrospective design and the limited sample size limit the quality of these studies. In the present issue of the Journal, Fischlein and colleagues ${ }^{8}$ report results from the first randomized controlled trial comparing sutureless versus stented valves. The Perceval Sutureless Implant versus StandardAortic Valve Replacement (PERSIST-AVR) trial demonstrates sutureless prostheses are not inferior to stented valves with respect to major adverse cerebral and cardiovascular events (MACCE) at 1 year. $^{8}$ Specifically, freedom from MACCE was $91.6 \%$ versus $92 \%$ in the sutureless and stented group, with similar hemodynamic performances. In addition, sutureless valves conferred an overall $20 \%$ reduction of cardiopulmonary and aortic crossclamp times, especially in the setting of minimally invasive surgery and combined procedures. Finally, sutureless valves were associated with a $7.5 \%$ absolute increased risk of pacemaker implantation. Results were quite expected; however, the methodology and the large sample size bring to a final conclusion that sutureless valves are safe and reduce operative times, although the rate of pacemaker insertion is greater.

Nevertheless, this study presents several limitations. First, definitions used for PERSIST-AVR are from Valve Academic Research Consortium (VARC-2) criteria, which were designed for transcatheter AVR clinical trials. ${ }^{9}$ According to them, valve reintervention was defined as additional valve prosthesis implanted within a previous 
implanted prosthesis because of suboptimal device position and/or function, during or after index procedure. In this regard, we do not know if surgeon had to come back on pump for repositioning the prosthesis because of paravalvular leakage. Conversely, the well-known guidelines for reporting mortality and morbidities after cardiac valve intervention define reintervention as any surgical or percutaneous interventional catheter procedure that repairs, otherwise alters or adjusts, or replaces a previously implanted prosthesis or repaired valve. ${ }^{10}$ Second, MACCE includes only valve-related mortality without including valve-related morbidity and need for pacemaker implantation. ${ }^{10}$ Thus, different definitions might modify the results of primary end point. Third, there is an overlap of information regarding hemodynamic performances of these valves. Specifically, effective orifice areas and gradients should be reported according valve size and not as an average of all valve sizes. However, comparison between the 2 groups is not easy, as a Perceval Small corresponds to a 19 - to $21-\mathrm{mm}$ annulus size, Medium to a $21-23 \mathrm{~mm}$, Large $23-25 \mathrm{~mm}$, and X-Large to a $25-27 \mathrm{~mm}$. Finally, this trial did not include patients undergoing right anterior minithoracotomy, which has been demonstrated to be superior in some outcomes compared with ministernotomy. ${ }^{11,12}$

In conclusion, PERSIST-AVR has shown to be not inferior to stented valve in patients undergoing AVR alone or in combination with coronary artery bypass grafting. Despite results that are not new, this trial has definitively confirmed what we already knew. It is now time to turn the page: we need to compare sutureless versus TAVR.

\section{References}

1. Al-AziziK, Hamandi M, Mack M. Clinical trials of transcatheter aortic valve replacement. Heart. 2019;105(Suppl 2):s6-9.

2. McClure RS, Narayanasamy N, Wiegerinck E, Lipsitz S, Maloney A, Byrne JG, et al. Late outcomes for aortic valve replacement with Carpentier-Edwards pericardial bioprosthesis: up to 17-year follow-up in 1000 patients. Ann Thorac Surg. 2010;89:1410-6.

3. Hamm CW, Beyersdorf F. GARY - the largest registry of aortic stenosis treatment worldwide. Eur Heart J. 2020;41:733-5

4. Miceli A, Lio A, Glauber M. Sutureless valves: a future without sutures. J Thorac Cardiovasc Surg. 2016;151:1627-8.

5. Powell R, Pelletier MP, Chu MWA, Bouchard D, Melvin KN, Adams C. The Perceval sutureless aortic valve: review of outcomes, complications, and future direction. Innovations (Phila). 2017;12:155-73.

6. Meuris B, Szecel D, Eurlings R, Rega F, Verbrugghe P. Sutureless AVR experience in a single center: 11 years of use in 468 patients; 2019. Available at: https:// www.aats.org/aatsimis/AATSWeb/Association/Meetings/Annual_Meeting/99th_ Annual_Meeting/AATS_99th_Annual_Meeting_Abstracts/2019-a-832-AATS. ASPX. Accessed November 14, 2019.

7. Meco M, Montisci A, Miceli A, Panini P, Donatelli F, Cirri S, et al. Sutureless Perceval aortic valve versus conventional stented bioprostheses: meta-analysis of postoperative and midterm results in isolated aortic valve replacement. J Am Heart Assoc. 2018;16:e06091.

8. Fischlein T, Folliguet T, Meuris B, Shrestha ML, Roselli EE, McGlothlin A, et al. Sutureless versus conventional bioprostheses for aortic valve replacement in severe symptomatic aortic valve stenosis. J Thorac Cardiovasc Surg. 2021;161: 920-32.

9. Kappetein P, Head SJ, Généreux P, Piazza N, van Mieghen NM, Blackstone EH, et al. Updated standardized endpoint definitions for transcatheter aortic valve implantation: the valve academic research consortium-2 consensus document. J Thorac Cardiovasc Surg. 2013;145:6-23.

10. Akins CW, Miller C, Turina MI, Kouchoukos T, Blacjstone EH, Grunkemeier GL, et al. Guidelines for reporting mortality and morbidities after cardiac valve intervention. J Thorac Cardiovasc Surg. 2008;135:732-8.

11. Miceli A, Santarpino G, Pfeiffer S, Murzi M, Gilmanov D, Concistré G, et al. Minimally invasive aortic valve replacement with Perceval S sutureless valve: early outcomes and one-year survival from two European centers. J Thorac Cardiovasc Surg. 2014;148:2838-43.

12. Miceli A, Murzi M, Gilmanov D, Fugà R, Ferrarini M, Solinas M, et al. Minimally invasive aortic valve replacement using right minithoracotomy is associated with better outcomes than ministernotomy. J Thorac Cardiovasc Surg. 2014;148:133-7. 